\title{
Imaginative Resistance, Narrative Engagement, Genre
}

\author{
Shen-yi Liao \\ Res Philosophica (forthcoming) ${ }^{\dagger}$
}

\begin{abstract}
Imaginative resistance refers to a phenomenon in which people resist engaging in particular prompted imaginative activities. On one influential diagnosis of imaginative resistance, the systematic difficulties are due to these particular propositions' discordance with real-world norms. This essay argues that this influential diagnosis is too simple. While imagination is indeed by default constrained by real-world norms during narrative engagement, it can be freed with the power of genre conventions and expectations.
\end{abstract}

Nothing is more free than the imagination of man, says David Hume in An Enquiry Concerning Human Understanding. Our pre-theoretical understanding agrees. In important ways, imagination seems to be the the opposite of belief: unbounded from actuality, free to wander through possibilia, and unconstrained by norms. However, in recent years philosophers have uncovered a curious collection of phenomena that challenges our pre-theoretical understanding of imagination, especially its alleged lack of normative governance. ${ }^{1}$ As a first pass, imaginative resistance is the collection of phenomena concerned with people's systematic difficulties with imagining particular propositions, notably morally deviant ones.

\footnotetext{
${ }^{*}$ I am most thankful to Kendall Walton for his attentive and critical guidance throughout the long development of this essay. For other helpful discussions and comments, I am thankful to Tamar Szabó Gendler, Sarah Buss, Ross Cameron, Victor Caston, Tyler Doggett, Andy Egan, Eduardo García-Ramírez, Allan Gibbard, Jim Hamilton, Daniel Jacobson, Marie Jayasekera, Lina Jansson, Jason Konek, Amy Lara, Sydney Levine, Eric Lormand, Molly Mahony, Ian McCready-Flora, Kengo Miyazono, Alex Plakias, David Plunkett, Sara Protasi, Laura Ruetsche, Tina Rulli, Neil Sinhababu, Brittani Sonnenberg, Nils-Hennes Stear, Eric Swanson, Dustin Tucker, participants of Lei Zhong's Standard Chinese philosophy salon, and many anonymous referees. Finally, I am thankful to Nina Strohminger and Chandra Sekhar Sripada, my collaborators on a companion article; our collaboration has significantly reshaped not only my thoughts on the issues discussed in this essay, but also my intellectual trajectory since.

${ }^{\dagger}$ Penultimate Version. This is a pre-copyedited and author-produced PDF of an article accepted for publication following peer review. For citation and reference, please see the definitive publisherauthenticated version forthcoming in Res Philosophica.

${ }^{1}$ Contemporary philosophical discussions of imaginative resistance began with Walton (1994), Moran (1994), and Gendler (2000). For overviews of the extensive literature that has developed since the early influential articles, see Liao and Gendler (2015) and Miyazono and Liao (2016).
} 


\section{$2 \cdot$ Shen-yi Liao $\cdot$ Imaginative Resistance, Narrative Engagement, Genre}

On one influential diagnosis of imaginative resistance, the systematic difficulties are due to these particular propositions' discordance with real-world norms. ${ }^{2}$ When a story says that female infanticide is morally right, people have a hard time really imagining so because this proposition is contrary to the moral norms that (we take to) hold in the real world. Other normatively deviant propositions can evoke imaginative resistance too. When a story says that a knock-knock joke told for the billionth time is still hilarious, people have a hard time imagining so because this proposition is contrary to the aesthetic norms that (we take to) hold in the real world. On this diagnosis, imaginative resistance shows that imagination is in fact constrained by norms-contrary to Hume's assertion and our pre-theoretical understanding.

This essay argues that this influential diagnosis is incomplete, and that a complete diagnosis requires acknowledging two additional features of imaginative resistance. First, imaginative resistance only shows that imagination can be constrained by norms under the particular frame of narrative engagement. That is, the normative constraint on imagination arises from a particular project we undertake-when we use imagination for the sake of gaining aesthetic pleasure from prompts such as fictions. Second, even during narrative engagement, the normative constraints on imagination can be moderated by genre. ${ }^{3}$ The appropriate classification of an imaginative prompt can change the norms that govern its fictional world and our corresponding imaginings. Together, these additional features of imaginative resistance suggest a more complicated diagnosis of imaginative resistance, on which not all propositions that are contrary to real-world norms inevitably evoke imaginative resistance, even if some do. Imagination is by default constrained by real-world norms during narrative engagement, but it can be freed with the power of genre conventions and expectations.

The ambition of this essay is to clarify the reciprocal relationships that exist between the three central concepts in the title. Primarily, it does so by showing that puzzling data concerning genre differences in imaginative resistance can be traced to genre's role in shaping the normativity and psychology of narrative engagements. But also, secondarily, it does so by using imaginative resistance as a test case for a more general picture concerning genre's role in narrative engagements. To realize this ambition, the essay will proceed in three steps. Section 1 clarifies the phenomena under investigation in three ways: it delineates the different facets of the phenomena, it frames the phenomena under the setting of narrative engagement, and it presents the puzzling data concerning genre differences. Section 2 synthesizes insights from literary theory and experimental psychology to generate a picture of genre's influence on the normative

\footnotetext{
${ }^{2}$ In my view, Gendler (2000, 2006), Walton $(1994,2006)$, Weatherson (2004), and Yablo (2002) all give versions of this diagnosis, which is further discussed in section 3.4. This diagnosis's influence has extended beyond narrow discussions of imaginative resistance. For example, Driver (2008) has used this diagnosis to elucidate the nature of human moral psychology.

${ }^{3}$ Others in the imaginative resistance literature have suggested that genre has a role to play in explaining imaginative resistance. For example, Gendler (2000) briefly mentions a distinction between distorting vs. non-distorting fictions, and Weinberg (2008) and Nanay (2010) mention genre in their accounts of the psychology of imaginative resistance. In my view, these early efforts have not captured genre's complexity and normative significance. Hence, while this essay is influenced by these early efforts, it also aims to go beyond them. Their influence is further discussed in section 1.3.
} 
and psychological aspects of narrative engagement. Section 3 then uses that picture to provide a more complete diagnosis of imaginative resistance, and discusses its relation to existing accounts of the phenomena.

\section{Imaginative Resistance}

\subsection{Delineating Resistance Phenomena}

The phenomena under investigation have to do with people's systematic difficulties with imagining particular propositions. Take Tamar Szabó Gendler's initial characterization as our rough guide:

When we engage in the sort of make-believe that contemplation of fictional scenarios evokes, we are largely unconstrained by what we take to be factual. [...] When an author invites us to contemplate a fictional scenario, she seems to have a great deal of freedom in how she directs our imagination. [...] But she seems to have much less freedom in what she makes fictionally true as far as matters of moral assessment are concerned. The trick that allows an author complete freedom in dictating whether or not character A murders character B is much less effective if what the author wants to dictate is that the murder is, for instance, praiseworthy, or noble, or charming, or admirable. So the puzzle is this: What explains why a trick so effective in so many realms is relatively ineffective here? (Gendler 2000, 56-58)

The heart of the phenomena involves an asymmetry. People's imaginings seem relatively unconstrained with respect to one type of proposition (for Gendler, the factual ones), but relatively constrained with respect to another type of proposition (for Gendler, the moral ones that are contrary to the real-world moral norms). And it is not just people's imaginings, but also what authors can do with works of fiction. Authors seem relatively unconstrained in specifying what is true in a fictional world with respect to one type of proposition (the factual ones), but relatively constrained with respect to another type of proposition (the moral ones).

Since Gendler's earliest essay on this topic, philosophers have made incremental refinements in characterizing the phenomena. For example, it is generally accepted now that the asymmetry is not precisely between factual propositions and moral propositions, but between broader types of propositions-such as descriptive vs. normative or non-response-dependent vs. response-dependent. To maintain neutrality, let us call the propositions that fall in the second category (moral, normative, or responsedependent), whatever its precise boundaries turn out to be, puzzling propositions.

The most important refinement, though, is the differentiation of various facets of the phenomena (Weatherson 2004; Walton 2006). This refinement clarifies the explananda of diagnoses of imaginative resistance. We can roughly divide these facets in a way that highlights two aspects of resistance phenomena that need to be explained: the normative and the psychological. (Of lesser importance, this refinement also suggests that better terminology is needed. Since the phenomena have to do with more than 


\section{4 - Shen-yi Liao - Imaginative Resistance, Narrative Engagement, Genre}

imagination, we should drop the confusing term "imaginative resistance" and dub them resistance phenomena.)

The normative aspect of resistance phenomena presents the fictionality puzzle, which asks why puzzling propositions are comparatively difficult to make fictionalthat is, true in a story. ${ }^{4}$ First, puzzling propositions bring out normative constraints on authorial freedom. Although authors usually have the authority to make a proposition fictional simply by saying so, it appears that they do not have the same freedom when it comes to puzzling propositions. Second, puzzling propositions also bring out normative constraints on readers' imagination. On arguably the most influential theory of fictionality today, what is fictional is what is to be imagined (Walton 1990). The normative constraints on fictional propositions therefore double as normative constraints on propositions that readers ought to imagine.

The psychological aspect of resistance phenomena presents two puzzles that concern people's actual responses to puzzling propositions. The imaginative puzzle asks why people in fact have comparative difficulties with imagining puzzling propositions. The phenomenological puzzle asks why people in fact experience a sense of jarring confusion when they encounter and attempt to imagine puzzling propositions. Moreover, the imaginative difficulties and the jarring phenomenology often go hand in hand. So, an additional desideratum for a diagnosis of resistance phenomena is to explain why the imaginative puzzle and the phenomenological puzzle are related in this way.

\subsection{Framing Resistance Phenomena}

It is not enough to delineate the puzzles associated with resistance phenomena. To truly grasp their nature, we have to situate them appropriately. There is an important feature of puzzling sentences and propositions that often goes unnoticed: puzzling propositions are not puzzling in themselves, but puzzling as parts of narratives. ${ }^{5}$ Early discussions of resistance phenomena make this feature evident; Walton (1994), Gendler (2000), Yablo (2002), and Weatherson (2004) are all explicit about introducing resistance phenomena with short stories. ${ }^{6}$ They do so because resistance phenomena arise during the mental project of narrative engagements.

\footnotetext{
${ }^{4}$ Like Gendler (2000), I want to emphasize that the difficulties with puzzling propositions are only comparative, relative to normal experiences with narratives, and not absolute.

${ }^{5}$ In contrast, Todd (2009) characterizes resistance phenomena as concerning "isolated, a-contextual single propositions". He consequently concludes that philosophers like Gendler and Walton are mistaken in thinking that there are genuine philosophical puzzles concerning a special class of isolated, a-contextual single propositions. While I agree with Todd that there are no genuine puzzles concerning particular propositions, I disagree with his characterization of resistance phenomena.

${ }^{6}$ Walton explicitly emphasizes the extent to which resistance phenomena are characteristic of narratives: "Can an author simply stipulate in the text of a story what moral principles apply in the fictional world, just as she specifies what actions characters perform? If the text includes the sentence, 'In killing her baby, Giselda did the right thing; after all, it was a girl' or 'The village elders did their duty before God by forcing the widow onto her husband's funeral pyre', are readers obliged to accept it as fictional that, in doing what they did, Giselda or the elders behaved in morally proper ways? Why shouldn't storytellers be allowed to experiment explicitly with worlds of morally different kinds, including ones even they regard as morally obnoxious?" (Walton 1994, 37; my emphases).
} 
A mental project is an activity that we undertake which have special normative and cognitive significance. This theoretical concept bears similarities to what Neil Van Leeuwen calls "practical setting". 7 Consider, for example, what Van Leeuwen says about the practical setting of make-believe.

... they've set up one such situation, or practical setting as I call it. In this case, it's the practical setting of make-believe. The proposal then, is that being in the practical setting of make-believe allows imaginings to take on a belief-like role in relation to desires in guiding actions, where it is the agent's awareness of that setting that constitutes the actions as full pretense. The setting of make-believe is constituted by a cluster of three shared expectations that agents have, when they are pretending together. ... (Van Leeuwen 2016)

We can draw general lessons about what I call mental project from Van Leeuwen's characterizations of the practical setting of make-believe. In general, a mental project can allow for ad hoc reconfigurations of an agent's cognitive apparatus. In the case of make-believe, according to Van Leeuwen, it allows for imaginings to play a more direct role in guiding actions. In general, a mental project can also temporarily reshape our expectations. In the case of make-believe, according to Van Leeuwen, an agent takes on particular sets of norms related to the pretense when she is in that practical setting.

Narrative engagement is the mental project we undertake when we recruit imagination for the sake of gaining aesthetic pleasure from imaginative prompts, such as fictional narratives. ${ }^{8}$ Imagination, in contrast, is a propositional attitude that is recruited in a variety of mental projects. ${ }^{9}$ For example, in addition to narrative engagement, imagination is recruited for make-believe and counterfactual reasoning.

Not all interactions with narratives that recruit imagination count as narrative engagements. A student could read a novel solely in preparation for an upcoming test. Even if he recruits his imagination in order to truly understand the fictional world of the novel, he seems to not be genuinely imaginatively engaging with the novel. Likewise, a censor for the film ratings board could watch a movie solely for its sexual and violent content. Even if she recruits her imagination in order to dutifully accomplish these evaluations, and consequently have the requisite vivid emotional responses, she seems to not be genuinely imaginatively engaging with the movie either.

\footnotetext{
${ }^{7}$ Van Leeuwen (2009) introduces the theoretical concept of practical setting, which in turn draws inspirations from Bratman (1992) (the concept of context in practical reasoning) and from Goffman (1974) (the concept of frame).

${ }^{8}$ The difference and relation between narrative engagement and imagination is analogous to the relationship between doxastic deliberation and belief that Shah (2003) and Shah and Velleman (2005) explicate. When belief is recruited in doxastic deliberation, they are governed by the norm of truth. But belief can also be governed by other norms when it is recruited in other mental projects. Moreover, doxastic deliberation involves not just belief, but also its relation to other attitudes and processes, such as inferential mechanisms.

${ }^{9}$ As the Stanford Encyclopedia of Philosophy entry on imagination (Gendler 2011) shows, the term "imagination" is highly ambiguous; nevertheless, referring to a propositional attitude is amongst the relatively standard uses of the term. Liao and Doggett (2014) provides an overview of the extensive debate on the nature of imagination in the attitudinal sense, and Liao and Gendler (2011) explores the various uses-that is, recruitments in different mental projects—of imagination in the attitudinal sense.
} 


\section{6 - Shen-yi Liao · Imaginative Resistance, Narrative Engagement, Genre}

What is distinctive of narrative engagement, in contrast with other (non-standard) interactions with narratives, is that one undertakes the project for the sake of gaining aesthetic pleasure from the work itself. (Of course, aesthetic pleasure need not be the only goal.) In order to derive enjoyment from the work itself-as opposed to from one's own creative imagination, for example-another important characteristic of narrative engagement is its inherent normative requirement to place one's imaginings and related psychological responses under the governance of the narrative's prescriptions. In slogan form: during narrative engagement, one aims one's imaginings at fictionality.

While resistance phenomena arise during narrative engagements, they do not typically arise with other mental projects that recruit imagination. Consider counterfactual reasoning as an example. ${ }^{10}$ During moral deliberation, one might ask oneself the question what if female infanticide were morally right. In reasoning about the answer to this question, one may need to vividly imagine female infanticide to be morally right and undergo related psychological responses, and then use those imaginings and psychological responses to draw out the potential consequences by imagining what else would be true in such a world. However, as we can observe from our own experiences, people tend not to have comparative difficulties with imagining a morally deviant proposition when they undertake the mental project of counterfactual reasoning for the sake of moral deliberation.

Framing resistance phenomena in the appropriate context-the mental project of narrative engagement-has profound implications for situating and explaining these phenomena. Instead of explaining resistance phenomena in isolation, we should situate them within a general framework of the normativity and psychology of narratives. The general normative question concerns the grounds on which a proposition gets to be fictional in a narrative. The general psychological question concerns the factors that causally influence people's responses to narratives. In this light, the fictionality, imaginative, and phenomenological puzzles associated with resistance phenomena are narrow variants of the general normative and psychological questions regarding narratives. This conception of resistance phenomena and the puzzles increases, rather than diminishes, their philosophical importance. In the same way that explaining specific Gettier cases can give us insight into the nature of knowledge, explaining resistance phenomena can give us insight into the normativity and psychology of narratives. In the same way that Gettier cases can act as tests on theories of knowledge, the puzzles associated with resistance phenomena can act as tests on accounts of narratives.

\subsection{Complicating Resistance Phenomena}

Recall the dialectic mentioned in the introduction. While early influential accounts of resistance phenomena tend to focus on the nature of puzzling propositions, it is distinctive of more recent works on resistance phenomena to focus on the difference that genre (and more broadly, context) makes (Liao and Gendler 2015). For example, Bence Nanay suggests that

\footnotetext{
${ }^{10}$ Byrne (2005) argues for the importance of imagination in counterfactual reasoning. Williamson (2007) leans on Byrne's account and grounds an epistemology of modality on counterfactual reasoning.
} 
... even the same readers may experience imaginative resistance when they encounter a sentence in one context, while not experiencing anything of that sort when they encounter it in another context. Some sentences that normally trigger imaginative resistance fail to do so if they are embedded in a surreal genre or a parody. (Nanay 2010, 589)

Nanay's suggestion is that genre can be a difference-maker in evoking or dissipating resistance phenomena. In making this suggestion, Nanay is echoing and exemplifying similar suggestions made in other recent works on imaginative resistance (Weinberg 2008; Willard 2015).

Most commonly, philosophers motivate the idea that genre can be a differencemaker in evoking or dissipating resistance phenomena with appeals to the diversity of moral landscapes in real-world narratives. For example, Jonathan Weinberg and Aaron Meskin suggest that

the morally and affectively disabling conditions of many cartoons [...] keep us from attending to the prima facie moral demands of sentient creatures like Wile E. Coyote or Daffy Duck, enabling us to take pleasure in a world where their pains are morally nugatory, or perhaps even praiseworthy. (Weinberg and Meskin 2006, 190)

Weinberg and Meskin are pointing to cartoons as one genre in which we sometimes do not typically find morally deviant propositions to be puzzling. In other words, a narrative's membership in the genre of cartoons has the capacity to dissipate resistance phenomena.

Furthermore, the idea that genre can be a difference-maker in evoking or dissipating resistance phenomena has recently been put to the empirical test. In one study, Shen-yi Liao, Nina Strohminger, and Chandra Sekhar Sripada present study participants with a pair of stories (in random order):

Seeing the Light. February 14th, 2010. Texas. There was only darkness. Everyone gathered around the preacher, Wayne Howell, for an announcement. "A message from the almighty came to me. The youngest girl must be sacrificed in order to bring back the light." They believed his every word. All eyes then turned to Mary, who had just given birth to a baby girl. Reluctantly, Mary gave her baby to the preacher to be sacrificed.

The Sun of the Second Creation. A long, long time ago, in the valley of Mexico, there was only darkness. Everyone gathered around the high priest, Cihuacoatl, for an announcement. "A message from the gods came to me. The youngest girl must be sacrificed in order to renew the sun." They believed his every word. All eyes then turned to Ixchel, who had just given birth to a baby girl. Reluctantly, Ixchel gave her baby to the high priest to be sacrificed.

After reading each story, participants were asked to consider the same proposition (with only the protagonist's name changed): Mary [Ixchel] did the right thing (Liao et al. 2014, 351). Specifically, participants were asked to assess whether the proposition is fictional 


\section{8 - Shen-yi Liao · Imaginative Resistance, Narrative Engagement, Genre}

in each of the two stories. (An earlier study showed that this question about fictionality generates the same pattern of results as an analogous question about imaginationnamely, whether participants found it easy or hard to imagine the proposition.)

Although the two stories have many surface similarities, they contain cues to different genres. "Seeing the Light" is a police procedural, but "The Sun of the Second Creation" is an Aztec myth. ${ }^{11}$ Liao, Strohminger, and Sripada found that genre can indeed make a difference to participants' fictionality judgment. Although participants thought that in the fictional world of "The Sun of the Second Creation" Ixchel's action is morally right, they thought that in the fictional world of "Seeing the Light" Mary's action is morally wrong. In other words, participants typically experienced resistance phenomena when prompted to imagine that the protagonist did the morally right thing with "Seeing the Light", but not with "The Sun of the Second Creation".

As is the case with other short stories that philosophers employ in this literature, the stories that Liao, Strohminger, and Sripada employ are necessarily schematic in order to bring out the relevant difference. ${ }^{12}$ Nevertheless, their results do cohere with suggestions that philosophers have made about genre's connection to resistance phenomena and the real-world examples that philosophers have pointed to. Collectively, these data points motivate a need to construct an explanation of resistance phenomena that gives genre its due.

\section{Genre and Narrative Engagement}

Literary theorist Tzvetan Todorov characterized genre as having dual functions: "as 'horizons of expectations' for readers and as 'models of writing' for authors" (Todorov 1990, 18). Genre influences both artists' constructions of narratives and audiences' experiences with them-in other words, both what is fictional and what is imagined. This section draws inspiration from Todorov's characterization of genre and synthesizes insights from humanistic and scientific inquiries on genre to elucidate genre's significance for the normativity and psychology of narrative engagement. ${ }^{13}$

\footnotetext{
${ }^{11}$ One might note that the two stories also differ in, for example, their time and place settings. I am inclined to count these differences as genre differences, since different genres can call for different time and place settings and different time and place settings can cue different genres. However, the same philosophical points in this essay can be made if we focused less on genre specifically and focused more on contextual factors generally. See Liao et al. (2014), footnote 37, for discussion of this complication.

${ }^{12}$ See Tanner (1994), Mothersill (2003), and Todd (2009) for cautionary notes about drawing philosophical conclusions from such schematic stories.

${ }^{13}$ There are few systematic discussions of genre in contemporary philosophical aesthetics. Furthermore, for the most part, contemporary analytic aestheticians have overlooked the development of genre theory in literature, film, and other media studies. (Currie (2004) and Laetz and Lopes (2008) are two notable exceptions.) For historical background of genre theory in these cognate fields, see the classic essays collected in Duff (2000). For contemporary discussions, see Frow (2006) and the essays collected in Dowd et al. (2006).
} 


\subsection{Genre}

At the most basic level, genres are simply groupings of narratives that are recognized by the relevant community as special. The notion of genre employed here is thus relatively broad and also includes what others might call medium, presentation, mode, or style. ${ }^{14}$ One important role that genres play is classifying narratives. Everyday discussions of novels, movies, and narratives in other media often invoke specific genres. At libraries and bookstores, works are often organized according to genres. Following Kendall Walton's landmark work on categories of art, whether a work is appropriately classified in a genre depends on a variety of factors: its relevant resemblance to other works in that genre, the artist's intentions, critical judgments, and that genre's propensity for aesthetic pleasure (Walton 1970). Usually, a work is appropriately classified in more than one genre, and the multiple genres of the work may overlap one another. Adjudicating the different factors when they conflict can sometimes be difficult and undoubtedly interestand context-dependent. Nevertheless, the frequent invocations of genres in everyday discussions of narratives demonstrate that people tend to have a good pre-theoretical grasp on how to classify narratives in the appropriate genres.

However, genre is important for explanations in aesthetics because individual genres are more than mere classifications. ${ }^{15}$ Genre also holds implications for the normativity and psychology of narrative engagement. ${ }^{16}$ Disagreements about genre in everyday discussions of narratives are often more than just disagreements about classifications. When people disagree about whether a novel is appropriately classified in the genre of magical realism or realistic fiction, they might also be disagreeing about whether it is literally true in the story-as opposed to merely metaphorical-that a character was washed into the world by a great tide of tears. When people disagree about whether a movie is appropriately classified in the genre of horror or the genre of black comedy, they might be also disagreeing about whether it would be fitting for them to laugh at a gruesome decapitation scene. Genre influences the propositions that are warranted to be fictional in a narrative and the ways that one ought to, and actually does, engage with a narrative.

\subsection{Convention}

On the normative side, genre gives authors conventions that constrain what could be made fictional. Fictional worlds are rich entities; the propositions that are fictional often far exceed the propositions that are directly expressed by a narrative. Principles of generation determine which non-explicitly-expressed propositions are warranted to be added to a fictional world outright, and which are warranted to be inferred from the

\footnotetext{
${ }^{14}$ In other words, I am including many groupings of narratives that are not always recognized as genres. However, whether a genre is salient depends on the context. Thus, a genre like experimental fiction can be salient in the context of literary criticism, but not so in the context of casual conversations.

${ }^{15}$ Contra Currie (2004), Liao (2014) argues for the legitimacy and importance of genre explanations in aesthetics, against a background pragmatist and pluralist understanding of aesthetic explanations.

${ }^{16}$ Liao (2013) and Liao and Protasi (2013) explore genre's contribution to another aspect of the normativity and psychology of narrative engagement: how narratives can be responsible for changes in our attitudes.
} 
explicitly-expressed propositions. ${ }^{17}$ For example, the proposition Sherlock Holmes has only one heart is plausibly fictional in the Sherlock Holmes novels, even though Arthur Conan Doyle never explicitly says so. The proposition is warranted to be fictional because real-world biological relationships tend to hold in the Holmes fictional world. We are warranted to infer the fictionality of the proposition Sherlock Holmes has only one heart from the fictionality of the explicitly-expressed proposition Sherlock Holmes is human. Only with these principles can rich fictional worlds be constructed from the few propositions explicitly expressed by words on a page or images on a screen.

As systematizations of the features common to works in a given genre, genre conventions constrain what is fictional because they constrain which implicit propositions and which inferential patterns are warranted for a fictional world. Conventions do not merely catalogue the common features, but also say something about the relationships between them. As a simplistic example, a convention of the science-fiction genre is that physical laws of the real world need not hold in the fictional world. In one sense, this convention is descriptive: it is in fact typical for works that are appropriately classified in science-fiction to include violations of real-world physical laws. In another sense, this convention is also normative: being appropriately classified in science-fiction warrants a work's inclusion of violations of real-world physical laws. Considered in the normative sense, genre conventions constrain the nature of relevant fictional worlds by contributing to the relevant principles of generation that govern the propositions warranted to be added or inferred.

\subsection{Expectation}

On the psychological side, genre gives readers expectations that govern imaginings and related psychological responses. During narrative engagement, people place their imaginings under a narrative's prescriptions. On arguably the most influential account of fictionality today, what is fictional is what a narrative prescribes its readers to imagine (Walton 1990). Hence, since the conventions of a narrative's genre constrain what is fictional, they also constrain what the narrative's readers are prescribed to imagine. In order to comply with a narrative's prescriptions, people align their expectations to the corresponding conventions. ${ }^{18}$ As a simplistic example, during a narrative engagement with a science-fiction work, a reader ought to accept as fictional and imagine claims that violate real-world physical laws. Generally speaking, genre conventions generate oughts about imaginings, and these oughts are the genre expectations that people employ during narrative engagements. ${ }^{19}$ The ability to employ the appropriate genre expectations

\footnotetext{
${ }^{17}$ Walton (1990) articulates the role that principles of generation play in generating fictional worlds, but does not explicitly consider genre as a way of specifying the relevant principles of generation. (However, he does say, for instance, that criticism requires familiarity with a work's "medium, genre, and representational tradition" (Walton 1990, 184).) Discussions in Lewis $(1978,1983)$ regarding "inter-fictional carry-overs" suggest some considerations of genre in generating fictional worlds.

${ }^{18}$ Weinberg and Meskin (2005) makes similar suggestions about the relationship between genre conventions and readers' expectations.

${ }^{19}$ These oughts have only conditional normativity. Just because one should play by a game's rules does not mean that one (unconditionally) should play that game. Similarly, just because one ought to imagine
} 
is a practical competence, or know-how, with respect to narrative engagements.

We can put more psychological substance on this philosophical theory by saying more about genre expectations' place in the architecture of the mind. Speculatively, genre expectations are story schemas that people employ during narrative engagements. ${ }^{20}$ During successful narrative engagements, readers employ genre schemas with high fluency: quickly, automatically, and unconsciously. In ideal circumstances, readers of narratives employ the appropriate genre expectations in their constructions of the fictional worlds. ${ }^{21}$ These expectations influence the readers' psychological responses to the narrative, including what they imagine. The presence of story schemas explains why, in typical narrative engagements, people tend to simply "go along with the story". When readers of narratives do not possess the requisite practical competence-in other words, when no appropriate genre expectations are accessible to them-they fall short of the ideal. In such cases, narrative engagements lose their typical ease because deliberate conscious efforts are demanded from the readers.

There are reciprocal interactions between genre expectation, fluency in narrative engagement, and aesthetic pleasure. On the one hand, when readers are able to undertake fluent narrative engagement by adopting appropriate genre expectations, they derive more aesthetic pleasure from the experience. ${ }^{22}$ When readers are unable to undertake fluent narrative engagement due to a lack of access to appropriate genre expectations, they might then turn away from the narrative and overlook its aesthetically worthwhile features. On the other hand, readers could also acquire appropriate genre expectations from compensating aesthetically worthwhile features and increased exposure to relevantly resembling works. ${ }^{23}$ Readers are then able to undertake fluent narrative engagement when increased aesthetic pleasure and familiarity encourage

according to a narrative's prescriptions does not mean that one (unconditionally) ought to undertake the project of narrative engagement. Unconditional normative constraints-moral, rational, or otherwisedictate which games we should play, as well as which narratives we should engage with. Conditional oughts about imaginings apply only once a reader has decided, consciously or unconsciously, to undertake narrative engagement.

${ }^{20}$ Mandler (1984) articulates the notion of a schema in processing stories. Frow (2006) also connects genre expectations with story schemas in the context of literary theory. While I will focus on schemas, the main points here can be understood in terms of other mental models also.

${ }^{21}$ However, as Liao (2013) notes, it is a common literary technique-in, for example, magical realismto have readers experience a temporary lack of fluency initially so that they can be alerted to and then come to employ the appropriate genre expectations after hermeneutic recalibration.

${ }^{22}$ Winkielman et al. (2003) and Reber et al. (2004) review empirical findings suggesting that the fluency of narrative engagement is a subjectual source of aesthetic pleasure. One possible explanation of the link between fluency and aesthetic pleasure is that fluency signifies an achievement of understanding. Thus, it might be especially pleasurable to engage with a complex narrative fluently, when one is unable to do so on a first pass due to complexity, because of the achievement in understanding that fluency signifies.

${ }^{23} \mathrm{By}$ no means are these the only ways that readers could acquire appropriate genre expectations. For example, intellectual understanding of the work's background, such as the importance of certain aesthetic features in a tradition, could also help readers form the appropriate genre expectations, especially regarding which features to attend to. However, compensating aesthetic pleasure and increased familiarity are particularly worth highlighting in this context because they are, in contrast with intellectual understanding, internal to aesthetic experiences. Developmentally, children usually begin to acquire different expectations for different genres between ages 3 and 5 (Woolley and Cox 2007), shortly after they acquire the capacity to separate fantasy from reality (Skolnick and Bloom 2006). 
them to overcome, and ultimately nullify, an initial lack of fluency.

The Rite of Spring offers a stark, if romanticized, illustration of the reciprocal interactions between expectations, fluency, and aesthetic pleasure. Famously, Stravinsky's percussive and dissonant ballet caused a riot in the theatre on its premiere. There were shouts, fistfights, and the Paris police had to come in at intermission. It is hard to imagine that the audience members found much aesthetic pleasure in their experiences with the work. One plausible factor that contributes to the audience members' responses is their lack of fluency in engaging with the piece, which results from their expectations of a ballet at that time. However, it is now widely recognized that The Rite of Spring is a revolutionary masterpiece, and it has influenced many subsequent compositions. The piece's wide recognition and influence open up two compatible explanations of why nowadays there are no longer shouts and fistfights, but only applause, at its performances. For one, even if an audience member experiences an initial lack of fluency in engagement, she might persist for the aesthetic pleasures expected to be found in the piece itself. For another, as the musical vocabulary used in The Rite of Spring became more commonplace as a result of its influence, the increase in familiarity with and exposure to this musical vocabulary also increases the fluency with which an audience member is able to engage with the piece. As people's experiences with The Rite of Spring demonstrate, a lack of appropriate genre expectations, and a corresponding lack of fluency, can sometimes be temporary rather than persistent.

\section{Genre and Imaginative Resistance}

The preceding picture reveals genre's influence on the normative and psychological aspects of narrative engagement. Genre conventions contribute to grounding the notion of fictionality, and genre expectations influence people's imaginings. With the resources that this picture provides, this section directly addresses the puzzles associated with resistance phenomena. To illustrate the solutions to the puzzles, we will return to the two stories mentioned in section 1.3, "Seeing the Light" (the police procedural that evokes resistance phenomena) and "The Sun of the Second Creation" (the Aztec myth that does not evoke resistance phenomena). By addressing all aspects of resistance phenomena, this section aims to show that genre occupies an important place in a unifying explanation of resistance phenomena.

\subsection{The Fictionality Puzzle}

We can see the role that genre conventions play in addressing the fictionality puzzle by elaborating on the contrast between the two stories presented earlier. "Seeing the Light" contains cues that place it in the genre of police procedural. The conventions of this genre is such that its fictional worlds are more or less like ours at a global level. While there could be differences in the specific events that occur, there could not be general differences such as differences in the physical laws or the moral norms that apply. So, when engaging with this story, readers are only warranted to import propositions that are actually true and employ inferential patterns that make sense in the real world. 
Since giving up one's baby for sacrifice violates real-world moral norms, doing so is also wrong according to the fictional moral norms of "Seeing the Light". The moral proposition Mary did the right thing by giving up her baby to be sacrificed, when placed in this story, evokes the fictionality puzzle because it is convention-discordant: the genre conventions that govern this fictional world forbid making a violation of real-world moral norms fictional. Moreover, recall that the normative constraints on what a reader ought to imagine doubles as normative constraints on what authors can make fictional. Hence, the moral proposition's convention-discordance also means that the author of "Seeing the Light" lacks the typical authorial freedom to make it true in the story just by saying so.

In contrast, "The Sun of the Second Creation" contains cues that place it in the genre of Aztec mythology. The conventions of this genre is such that its fictional worlds could be importantly unlike ours at a global level, particularly in the moral dimension. When engaging with this story, readers are warranted to not import real-world moral norms into this story's fictional world but instead take, say, a specific version of divine command theory to hold in the fictional world. So readers are warranted to take the actions that the gods command to be morally right to be indeed morally right in the fictional world. Since the gods demand so, giving up one's baby for sacrifice is not wrong according to the fictional moral norms of "The Sun of the Second Creation". The moral proposition Ixchel did the right thing by giving up her baby to be sacrificed, when placed in this story, does not evoke the fictionality puzzle because it is conventionconcordant: the genre conventions that govern the fictional world of "The Sun of the Second Creation" permit making a violation of real-world moral norms fictional. Hence, for the same reason as before, the moral proposition's convention-concordance also means that the author of "The Sun of the Second Creation" possesses the typical authorial freedom to make it true in the story just by saying so.

A proposition's genre convention-discordance is one factor that contributes to the comparative difficulties with making it fictional. Although conventions, like other norms, can be broken or reshaped, more effort and skill on an author's part are required. As "models of writing" for authors-in Todorov's words-genre conventions constrain authorial freedom. A proposition is not always made fictional just because the author says so. Although authors have a great deal of control regarding the fictional worlds they create, they cannot decide which propositions get to be fictional simply by fiat. If all other features of a narrative were to indicate strongly that a work is a realistic fiction and not a science fiction, then it would be comparatively difficult for the author to make the convention-discordant proposition there is a spaceship that can travel faster than the speed of light fictional. Moreover, although authors have a great deal of control regarding the appropriate genres for their works, they cannot decide which genre conventions apply simply by fiat either. Douglas Adams cannot make The Hitchhiker's Guide to the Galaxy a realistic fiction, no matter how much he sincerely intends it to be. It clearly does not resemble other realistic fictions, no critic judges it as a realistic fiction, and engaging with it as a realistic fiction would not produce more interesting or pleasing aesthetic experiences. Since multiple criteria determine the appropriate genre for a fiction, authorial intention must be weighed against other criteria and may 
sometimes be overridden. Hence, authorial freedom is neither absolute when it comes to the appropriate genre of a fiction nor absolute when it comes to the conventions that govern what could be made fictional.

Genre conventions' constraint on fictionality urges us to rethink our understanding of resistance phenomena. Much of the literature has singled out moral deviance as the focus of resistance phenomena. However, the variety of genres and genre conventions gives us reason to question the primacy of moral deviance. Some philosophers have already argued that moral deviance is not necessary to evoke resistance phenomena (Yablo 2002; Weatherson 2004). I am arguing that the variance in genre conventions that govern the moral dimension of fictional worlds shows that moral deviance is not sufficient to evoke resistance phenomena by itself either. Instead, morally deviant propositions evokes resistance phenomena when they are also genre conventiondiscordant.

Kendall Walton once asked, "There is science fiction; why not morality fiction?" (Walton 1994, 37). Are there genres with conventions that permit deviations from real-world moral norms in the same way that the conventions of science fiction permit deviation from real-world physical laws? As "The Sun of the Second Creation" demonstrates, the answer is "yes". There is an important symmetry between physics and morality in fictions: violations of real-world physical laws are convention-discordant in some genres but not others, and violations of real-world moral norms are conventiondiscordant in some genres but not others. ${ }^{24}$ As noted in section 1.3, other philosophers have suggested that real-world examples of morality fictions might be found in genres such as cartoons, surrealist fiction, and fairytales and fables. ${ }^{25}$ Although these genres are not defined by moral deviances, their conventions nevertheless permit violations of real-world moral norms. Once we expand our stock of examples beyond the realistic fictions that often serve as paradigms in aesthetic discussions, it becomes clear that morality fictions are possible-indeed, many of them are actual-and resistance phenomena are about far more than moral deviance. The diversity found in the moral landscapes of fictional worlds is made possible by the different genre conventions that govern various fictional worlds.

\subsection{The Imaginative Puzzle}

We can also see the role that genre expectations play in addressing the imaginative puzzle by elaborating on the difference between the two stories earlier. The same moral proposition, Mary [Ixchel] did the right thing by giving up her baby to be sacrificed, is comparatively more difficult to imagine when presented in "Seeing the Light" than when presented in "The Sun of the Second Creation". This asymmetry in people's

\footnotetext{
${ }^{24}$ In conversation, Kendall Walton points out a curious asymmetry between science fiction and some genres of morality fictions. While science fiction permits all kinds of deviations from real-world physical laws, some genres of morality fictions, such as mythology, permit only specific deviations from real-world moral norms. Despite the curiosity, this asymmetry does not undermine the present modest claim, that there are genres in which deviations from real-world moral norms are permitted.

${ }^{25}$ In addition to the example fromWeinberg and Meskin (2006) mentioned in section 1.3, see also discussions in Weinberg (2008), Todd (2009), Nanay (2010), and Willard (2015).
} 
typical psychological responses exist because people typically employ different genre expectations during narrative engagement with the two stories.

Ultimately, the different genre expectations are grounded in the different corresponding genre conventions that govern the stories. When reading the police procedural "Seeing the Light", competent readers typically automatically and unconsciously expect the fictional world to have the same moral norms as the real world. So readers have comparative difficulties with imagining that it is morally right for Mary to give up her baby for sacrifice because the proposition is expectation-discordant. In contrast, when reading the Aztec myth "The Sun of the Second Creation", competent readers typically do not automatically and unconsciously expect the fictional world to have the same moral norms as the real world. So readers have no comparative difficulties with imagining that it is morally right for Ixchel to give up her baby for sacrifice because the proposition is expectation-concordant.

A proposition's genre expectation-discordance is one factor that contributes to the comparative difficulties with imagining it. As Todorov suggests, genre expectations constrain what readers can easily imagine in the same way that genre conventions constrain what authors can easily make fictional. A proposition is puzzling when readers have no existing schemas to make sense of the proposition and no inclination to form new schemas or adjust existing ones. In such cases, readers default to expecting the fiction that contains the proposition to be realistic in all aspects. Although readers could exert deliberate and conscious mental effort to override the realist expectations to imagine the puzzling proposition, these expectations nevertheless make the puzzling proposition comparatively difficult to imagine due to the additional mental effort required.

As is the case with genre conventions, readers' expectations can sometimes be challenged and reshaped when there are sufficient rewards for doing so. Some of the best works, one might argue, are precisely the ones that challenge readers to form new genre expectations or reshape their existing ones. A diligent and skillful author might be able to make initially puzzling propositions more easily imaginable by rewarding readers with worthwhile aesthetic features in the work. Hence, it is only when readers cannot find compensating aesthetic pleasure for the recalibration and re-habituation of their expectations that they default to realist expectations. Note that the default of realist expectations applies for all dimensions of a fictional world, not just the moral and evaluative dimensions. Readers do not start off thinking every fiction that they encounter is a science fiction and expecting violations of real-world physical laws. Their default is simply to preserve systematic real-world features as much as possible unless genre cues indicate otherwise. ${ }^{26}$

So, let us ask again, why does "Seeing the Light" evoke resistance phenomena? To begin, although there are genres in which morality fictions can be found, this story does not exhibit cues for any of them. More importantly, there are no apparent aesthetically worthwhile features of the work that could compensate for or nullify the initial experience of imaginative difficulties. Frankly, "Seeing the Light" is an

\footnotetext{
${ }^{26}$ Weisberg and Goodstein (2009) and Weisberg et al. (2013) give evidence from developmental psychology for people's reality bias in constructing fictional worlds.
} 
unremarkable story in its own right: the characters are hardly identifiable, the storyline is hardly creative, and the writing is hardly stylish. However, such unremarkable short stories are standard in the resistance phenomena literature because-after allit is philosophers, and not fiction writers, who have authored them. Talented flash fiction writers like Lydia Davis can use few words to great effect. Perhaps these writers could have challenged and reshaped readers' expectations with the same word count without resorting to generic devices. Unfortunately for philosophers in the resistance phenomena literature, they are not so talented in this respect. ${ }^{27}$ Without a diligent and skillful author, an unremarkable fiction like "Seeing the Light" simply cannot do enough to persuade readers to recalibrate and rehabituate their expectations. Consequently, readers have comparative difficulties with imagining a proposition that is discordant with respect to all of their accessible genre schemas.

\subsection{The Phenomenological Puzzle}

In addition to addressing the imaginative puzzle, genre expectations also have a role in addressing the phenomenological puzzle. What drives the phenomenological experience that "Seeing the Light" evokes is the lack of the appropriate genre expectations that make sense of the story. Without appropriate genre expectations, or schemas, people's narrative engagement with this story ceases to be fluent-that is, quick, automatic, and unconscious. The lack of cognitive ease and the conscious effort demanded manifest themselves as the jarring confusion that characterizes resistance phenomenology.

As is the case with the difficulties associated with the imaginative puzzle, the experiences associated with the phenomenological puzzle could be either temporary or persistent. Some literary works purposefully evoke a temporary sense of jarring confusion as a distancing device to force readers to reconsider and reinterpret earlier parts of the work. Thus, the phenomenology of resistance by itself need not be philosophically puzzling. It is only when this phenomenology persists even after repeated readings of the whole work that there is a philosophical puzzle to be explained.

Genre expectations help us understand why the jarring phenomenology frequently co-occur with the imaginative difficulties, whether they are temporary or persistent. Both psychological responses result from a lack of appropriate genre expectations and a corresponding lack of fluency in narrative engagement. Although the imaginative puzzle and the phenomenological puzzle are conceptually distinct, they have the same psychological basis. Only by recognizing the role of genre expectations in the psychology of fictions can we arrive at a unifying explanation of the psychological aspect of resistance phenomena.

\footnotetext{
${ }^{27}$ Todd (2009) also highlights the aesthetic flaws of philosophers' stories. I deny that aesthetic flaws directly influence readers' comparative difficulties with imagining puzzling propositions, as Todd suggests. Instead, I say that they only indirectly influence readers' narrative engagements via the circuitous relationships between genre expectations, fluency, and aesthetic pleasure. Uncovering those relationships increases our understanding of the imaginative puzzle and the psychology of narrative engagement.
} 


\subsection{The Genre Account, in the Grand Scheme of Things}

We have arrived at an account of resistance phenomena that highlights genre's role. The genre account says that puzzling propositions are comparatively difficult to make fictional because they are genre convention-discordant, comparatively difficult to imagine because they are genre expectation-discordant, and generate a sense of jarring confusion partly because readers lack the requisite genre expectations for fluent narrative engagement. The genre account is not the whole story, but it is an important supplement to existing understanding of resistance phenomena.

The attraction of the genre account can be seen by showing why the early, influential diagnosis of resistance phenomena remains incomplete. Recall from the introduction that, in explaining resistance phenomena, these accounts all emphasize particular propositions' discordance with real-world norms and readers' actual evaluative attitudes and responses. However, this emphasis is explicated in terms of different mechanisms by different accounts. Mechanistically, Gendler $(2000,2006)$ and Yablo (2002) focus on the concepts invoked in puzzling propositions. Fiction authors cannot determine how moral concepts apply. Thus, according to these philosophers, asking readers to apply a moral concept differently than they actually would tends to evoke resistance phenomena. Mechanistically, Walton (1994, 2006) and Weatherson (2004) focus on the supervenience relations that link higher-level claims to their lower-level bases. Fiction authors can change the lower-level claims that are fictional, but they cannot change the supervenience relations that link higher-level claims, such as moral claims, to their lower-level bases. Thus, according to them, violating the moral supervenience relations that are taken to actually hold tends to evoke resistance phenomena.

Despite their mechanistic differences, these accounts all suffer from the same problem due to their fundamental similarity in focusing on the real world and actual responses: as they currently stand, they cannot help us explain why the same moral proposition evokes resistance phenomena in "Seeing the Light" but not in "The Sun of the Second Creation". For Gendler and Yablo, the relevant actual concept application regarding the moral rightness of giving up one's baby for sacrifice is the same irrespective of which story we are engaging with. For Walton and Weatherson, the relevant supervenience relations that actually hold between moral rightness and relevant lowerlevel bases is the same irrespective of which story we are engaging with. Therefore, they all have to say the same thing about the respective moral proposition of the two stories: either both are puzzling or neither are. As such, they are committed to say the wrong thing about one of the two stories. In contrast, the genre account can avoid this problem because it allows fictional worlds of different genres to have different conceptapplicability conditions and different fictional supervenience relationships-in virtue of the different genre conventions that apply.

A complete diagnosis of resistance phenomena must take into account multiple factors, including both the real-world norms and actual evaluations and responses as well as genre. This explanatory cosmopolitanism is necessary because the normativity and psychology of narrative engagement are complicated matters. As the field of literary criticism demonstrates, theorists lean on multiple factors-some formal, some 
historical, and some institutional-in deciding what is fictional in a given narrative. In everyday disagreements about fictions, multiple factors influence people's psychological responses. The same heartbreak soliloquy can cause a romantic to cry and a cynic to laugh. Putting resistance phenomena in their proper context-narrative engagementstherefore urges us to recognize their complexity. 


\section{References}

Bratman, M. E. (1992). Practical reasoning and acceptance in a context. Mind, 101:1-15.

Byrne, R. M. J. (2005). The Rational Imagination: How People Create Alternatives to Reality. MIT Press, Cambridge, MA.

Currie, G. (2004). Genre. In Arts and Minds, chapter 3, pages 43-62. Oxford University Press, New York.

Dowd, G., Stevenson, L., and Strong, J., editors (2006). Genre Matters. Intellect Ltd., Portland, OR.

Driver, J. (2008). Imaginative resistance and psychological necessity. Social Philosophy and Policy, 25(1):301-313.

Duff, D., editor (2000). Modern Genre Theory. Longman Publishing Group, New York.

Frow, J. (2006). Genre. Routledge, New York.

Gendler, T. S. (2000). The puzzle of imaginative resistance. The Journal of Philosophy, 97(2):5581.

Gendler, T. S. (2006). Imaginative resistance revisited. In Nichols, S., editor, The Architecture of the Imagination, pages 149-173. Oxford University Press, New York.

Gendler, T. S. (2011). Imagination. In Zalta, E. N., editor, Stanford Encyclopedia of Philosophy. Center for the Study of Language and Information, Stanford University, Stanford, spring 2011 edition.

Goffman, E. (1974). Frame Analysis. Harvard University Press, Cambridge, MA.

Laetz, B. and Lopes, D. M. (2008). Genre. In Livingston, P. and Plantinga, C., editors, The Routledge Companion to Philosophy and Film, pages 152-161. Routledge, New York.

Lewis, D. K. (1978). Truth in fiction. American Philosophical Quarterly, 15:261-280.

Lewis, D. K. (1983). Postscripts to "Truth in fiction". In Philosophical Papers, volume 1, pages 276-280. Oxford University Press, New York.

Liao, S. (2013). Moral persuasion and the diversity of fictions. Pacific Philosophical Quarterly, 94(2):269-289.

Liao, S. (2014). Explanations: aesthetic and scientific. Royal Institute of Philosophy Supplement, 75:127-149.

Liao, S. and Doggett, T. (2014). The imagination box. The Journal of Philosophy, 111(5):259-275.

Liao, S. and Gendler, T. S. (2011). Pretense and imagination. Wiley Interdisciplinary Reviews: Cognitive Science, 2(1):79-94.

Liao, S. and Gendler, T. S. (forthcoming 2015). The problem of imaginative resistance. In Gibson, J. and Carroll, N., editors, The Routledge Companion to Philosophy of Literature. Routledge, New York. 
Liao, S. and Protasi, S. (2013). The fictional character of pornography. In Maes, H., editor, Pornographic Art and the Aesthetics of Pornography, pages 100-118. Palgrave Macmillan, New York.

Liao, S., Strohminger, N., and Sripada, C. S. (2014). Empirically investigating imaginative resistance. British Journal of Aesthetics, 54(3):339-355.

Mandler, J. M. (1984). Stories, Scripts, and Scenes: Aspects of Schema Theory. Lawrence Erlbaum Associates, Hillsdale, NJ.

Miyazono, K. and Liao, S. (forthcoming 2016). The cognitive architecture of imaginative resistance. In Kind, A., editor, The Routledge Handbook of Philosophy of Imagination. Routledge, New York.

Moran, R. (1994). The expression of feeling in imagination. The Philosophical Review, 103(1):75106.

Mothersill, M. (2003). Make-believe morality and fictional worlds. In Bermúdez, J. L. and Gardner, S., editors, Arts and Morality, pages 74-94. Routledge, New York.

Nanay, B. (2010). Imaginative resistance and conversational implicature. The Philosophical Quarterly, 60:586-600.

Reber, R., Schwarz, N., and Winkielman, P. (2004). Processing fluency and aesthetic pleasure: Is beauty in the perceiver's processing experience? Personality and Social Psychology Review, 8:364-382.

Shah, N. (2003). How truth governs belief. The Philosophical Review, 112(4):447-482.

Shah, N. and Velleman, J. D. (2005). Doxastic deliberation. The Philosophical Review, 114(4):497-534.

Skolnick, D. and Bloom, P. (2006). What does Batman think about SpongeBob? children's understanding of the fantasy/fantasy distinction. Cognition, 101:B9-B18.

Tanner, M. (1994). Morals in fiction and fictional morality (II). Proceedings of The Aristotelian Society, Supplementary Volumes, 68:51-66.

Todd, C. (2009). Imaginability, morality, and fictional truth: Dissolving the puzzle of 'imaginative resistance. Philosophical Studies, 143(2):187-211.

Todorov, T. (1990). Genre in Discourse. Cambridge University Press, New York.

Van Leeuwen, N. (2009). The motivational role of belief. Philosophical Papers, 38(2):219-246.

Van Leeuwen, N. (forthcoming 2016). Imagination and action. In Kind, A., editor, The Routledge Handbook of Philosophy of Imagination. Routledge, New York.

Walton, K. L. (1970). Categories of art. The Philosophical Review, 79(3):334-367.

Walton, K. L. (1990). Mimesis as Make-Believe. Harvard University Press, Cambridge, MA.

Walton, K. L. (1994). Morals in fiction and fictional morality (I). Proceedings of The Aristotelian Society, Supplementary Volumes, 68:27-50. 
Walton, K. L. (2006). On the (so-called) puzzle of imaginative resistance. In Nichols, S., editor, The Architecture of the Imagination, pages 137-148. Oxford University Press, New York.

Weatherson, B. (2004). Morality, fiction, and possibility. Philosophers' Imprint, 4(3):1-27.

Weinberg, J. M. (2008). Configuring the cognitive imagination. In Stock, K. and Thomson-Jones, K., editors, New Waves in Aesthetics, pages 203-223. Palgrave Macmillan, New York.

Weinberg, J. M. and Meskin, A. (2005). Imagine that! In Kieran, M., editor, Contemporary Debates in Aesthetics and the Philosophy of Art, pages 222-235. Blackwell, Malden, MA.

Weinberg, J. M. and Meskin, A. (2006). Puzzling over the imagination: Philosophical problems, architectural solutions. In Nichols, S., editor, The Architecture of the Imagination, pages 175202. Oxford University Press, New York.

Weisberg, D. S. and Goodstein, J. (2009). What belongs in a fictional world? Journal of Cognition and Culture, 9(1-2):69-78.

Weisberg, D. S., Sobel, D. M., Goodstein, J., and Bloom, P. (2013). Young children are realityprone when thinking about stories. Journal of Cognition and Culture, 13(3-4):383-407.

Willard, M. B. (manuscript 2015). Stop over-analyzing it: The puzzle of historical inaccuracy and the pragmatic interpretation of imaginative resistance. Unpublished manuscript.

Williamson, T. (2007). The Philosophy of Philosophy. Wiley-Blackwell, Malden, MA.

Winkielman, P., Schwarz, N., Fazendeiro, T. A., and Reber, R. (2003). The hedonic marking of processing fluency: Implications for evaluative judgment. In Musch, J. and Klauer, K. C., editors, The Psychology of Evaluation: Affective Processes in Cognition and Emotion, pages 189-217. Lawrence Erlbaum Associates, Mahwah, NJ.

Woolley, J. D. and Cox, V. (2007). Development of beliefs about storybook reality. Developmental Science, 10(5):681-693.

Yablo, S. (2002). Coulda, woulda, shoulda. In Gendler, T. S. and Hawthorne, J., editors, Conceivability and Possibility, pages 441-492. Oxford University Press, New York. 